\title{
Acetazolamide in the treatment of alternating hemiplegia of childhood: A case report with an eighteen month follow up
}

\author{
*Soumya Roy ${ }^{1}$, Subroto Chakrabartty $^{1}$, Swati Chakravarti $^{1}$, Santanu Barman $^{1}$, Sumit Datta Majumdar $^{1}$ \\ Sri Lanka Journal of Child Health, 2020; 49(2): 182-184 \\ DOI: http://dx.doi.org/10.4038/sljch.v49i2.8970 \\ (Keywords: Alternating hemiplegia of childhood, refractory seizure, hemiplegia, acetazolamide, neurology)
}

\begin{abstract}
Introduction
Alternating hemiplegia of childhood (AHC) is an intriguing clinical condition rarely reported in the literature. The dramatic sequence of events is clinically perplexing and difficult to explain. We encountered such a child who had repeated attacks of either left-sided or right-sided hemiparesis. He responded remarkably to acetazolamide along with an antiepileptic.
\end{abstract}

\section{Case report}

A five year and eight month old boy had a history of excessive crying during bathing which was followed by tingling pain in left lower limb, and subsequently flaccid hemiparesis. Within minutes, the left upper limb was also similarly affected. Within the next half an hour, the child proceeded to have headache, vomiting and fever, with dysarthria and then fell asleep. Within a day or two the child developed focal clonic seizures in the ipsilateral limb. Over the next couple of days, the seizures responded gradually to antiepileptic drugs and the hemiparesis showed complete recovery. After the hemiparesis had recovered, we noticed features of cerebellar ataxia and occasional drooling of saliva. Recovery of hemiparesis did not stop occasional twitching, clonic movements of the ipsilateral limb parts and difficulty in fine motor activities including wearing of shoe. Higher functions, sensory and autonomic functions, motor tone and power were intact. Systemic examination was normal.

The history revealed that he was absolutely well till five years of age. Eight months ago, he had a fall during playing, following which he experienced a similar episode. Then he went on having such attacks after every forty-five to sixty days, with

${ }^{1}$ Institute of Child Health, Kolkata, India

*Correspondence: dr.roy85@gmail.com

(iD)

orcid.org/ 0000-0002-4897-6518

(Received on 23 February 2017: Accepted after revision on 24 September 2018)

The authors declare that there are no conflicts of interest

Personal funding was used for the project.

Open Access Article published under the Creative

Commons Attribution CC-BY (cC) (P) periods of well-being in between. It is notable that, while he had left-sided hemiparesis in three episodes, the remaining two episodes were on the right-side. Bathing was apparently the trigger in three episodes. Child had a term vaginal delivery and was born of a non-consanguineous marriage. Perinatal history, developmental milestones and intellectual functions were normal. There was no family history of migraine or seizures. His elder sister also used to have similar attacks, starting from seven years of age, and passed away six years later from an undocumented cause.

Complete haemogram, C-reactive protein, liver and renal functions, electrolytes, ammonia, lactate, antinuclear antibodies and urine protoporphyrin were normal. An electroencephalogram (EEG) done during the second attack showed epileptiform activity lateralised to the right temporo-occipital region. Magnetic resonance imaging (MRI) and magnetic resonance spectroscopy of the brain were normal. Magnetic resonance angiogram showed reduced peripheral branches of the left middle cerebral artery (Figure 1).

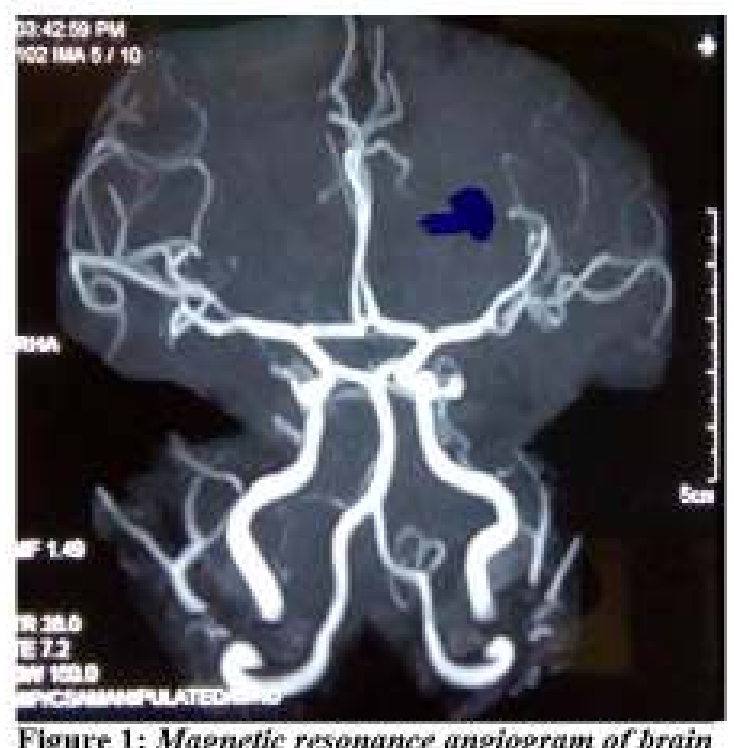

Figure 1: Magnetic resonance angiogram of brain showing reduced peripheral branches of left middle cerebral artery

We started flunarizine $0.3 \mathrm{mg} / \mathrm{kg} /$ day and clobazam $0.6 \mathrm{mg} / \mathrm{kg} /$ day in two divided doses with no improvement. Levetiracetam $20 \mathrm{mg} / \mathrm{kg}$ /day and valproate $60 \mathrm{mg} / \mathrm{kg} /$ day in two divided doses were 
then added. All the drugs failed to control seizure activity. Midazolam was of some use during the active state. Then we added acetazolamide 50 $\mathrm{mg} / \mathrm{kg} /$ day in three divided doses to the existing regimen, following which, symptoms gradually started improving. On day eight of admission, we withdrew flunarizine and clobazam and decreased valproate to $30 \mathrm{mg} / \mathrm{kg} /$ day (keeping levetiracetam in the same dose). We perceived remarkable improvement after one week. Subsequently he was discharged with advice of follow-up.

He was followed up monthly for one year. There were no further attacks during the whole year. Acetazolamide and valproate were gradually reduced to $20 \mathrm{mg} / \mathrm{kg} /$ day and $25 \mathrm{mg} / \mathrm{kg} / \mathrm{day}$ respectively. Neurological functions including intelligence and cognition stayed normal. Cerebellar signs markedly disappeared and he could walk in a straight line. He could recite poems in two languages with appropriate gestures and do simple mathematics. Fine motor skills improved and involuntary movements disappeared, so that he could write easily. After one year, acetazolamide was gradually stopped, keeping valproate as monotherapy, but after five days of withdrawal of acetazolamide, he again had an attack of left-sided hemiparesis with seizures. This compelled us to start acetazolamide once again. Follow up over the next six months has revealed the child to be free of any further episodes.

\section{Discussion}

AHC is a unilateral or bilateral flaccid hemiplegia, of sudden or gradual onset, which stays for minutes to weeks and may alternate between sides of the body. There is associated pseudobulbar palsy and often changes in skin colour, temperature and behaviour with sweating, restlessness, tremor, screaming and pain ${ }^{1}$. Bathing, stress or some foods may act as trigger. Hemiplegia ceases immediately on sleep and may recur 15 to 20 minute after waking $^{1}$. Forty one percent of patients have convulsions (tonic, tonic-clonic or myoclonic), with altered consciousness ${ }^{2}$. Seizures increase with age. There may be dystonia and choreoathetosis ${ }^{3}$. EEG may be normal or show generalized background slowing. Seventy eight percent have normal MRI or computed tomography (CT) scan of brain ${ }^{2,4}$. Fifty six percent of patients have their first attack before six months age ${ }^{1}$. Nystagmus is the most frequent $\operatorname{sign}^{2,3}$ and occurs within two days of life in $33 \%$ of patients and on or before the age of three months in $83 \%$ of patients ${ }^{2}$. As the disease progresses, nonparoxysmal features like motor deficit, ataxia, cognitive deficit and mental retardation ${ }^{2,3,5}$ persist in between the episodes of hemiparesis ${ }^{6}$.

AHC occurs due to mutations in ATP1A3 gene, which encodes alpha3-subunit of $\mathrm{Na}+/ \mathrm{K}+$-ATPase transporter of cardiac and neuronal tissue. Hence cardiac surveillance is needed as repolarisation abnormalities and intraventricular conduction delay can occur ${ }^{7}$. AHC is extremely rare, affecting one in a million. No protocol exists for treatment of AHC and flunarizine has mostly been used. However little above $50 \%$ patients have reduced duration and severity of attacks and $25 \%$ showed reduced frequency with flunarizine ${ }^{5}$ Although benzodiazepines, barbiturates, carbamazepine and valproate have also been tried, they met limited success.

From a study of the literature, we noted that historically AHC was a subtype of migraine till ICHD-2 omitted AHC from migraine spectrum ${ }^{8}$. In fact many symptoms of AHC are similar to familial hemiplegic migraine type-2. Thus we believe that, as acetazolamide is an established treatment of migraine, it had worked in our patient also. In fact Camfield and Andermann (2006) also had similar results with acetazolamide on two patients of $\mathrm{AHC}^{9}$. In the absence of any accepted treatment protocol, we suggest physicians include drugs of migraine spectrum, most importantly acetazolamide, into the treatment regimen of refractory AHC cases.

\section{References}

1. Haffejee S, Santosh PJ. Treatment of alternating hemiplegia of childhood with aripiprazole. Development Medicine and Child Neurology 2009; 51 (1): 74-7. https://doi.org/10.1111/j.14698749.2008.0 3192.x

PMid: 19087103

2. Sweney MT, Silver K, Gerard-Blanluet M, Pedespan JM, Renault F, Arzimanoglu A, et al. Alternating hemiplegia of childhood: early characteristics and evolution of a neurodevelopmental

syndrome. $\quad$ Pediatrics 2009; 123 (3): e534-41.

https://doi.org/10.1542/peds.2008-2027

PMid: 19254988

3. Silver K, Andermann F. Alternating hemiplegia of childhood: a study of 10 patients and results of flunarizine treatment. Neurology 1993; 43 (1): 36-41. https://doi.org/10.1212/WNL.43.1_Part_1. 36

PMid: 8423908

4. Mulas F, Smeyers P, Barbero P, Pitarch I, Velasco RP. Alternating hemiplegia in 
young babies". Rev Neurol (in Spanish) 2002; 34 (2): 157-62.

PMid: 11988911

5. Neville BG, Ninan M. The treatment and management of alternating hemiplegia of childhood. Development Medicine and Child Neurology 2007; 49 (10): 777-80. https://doi.org/10.1111/j.14698749.2007.0 0777.x

PMid: 17880649

6. Alternating Hemiplegia of Childhood Foundation. "What is AHC?" www.ahckids.org/education/what-is-ahc/ [Date of access 25/4/2015]

7. Jaffer F, Avbersek A, Kaski JP, Parton M, Houlden H, Hanna MG, et al. Cardiac features in adults with alternating hemiplegia. Journal of Neurology, Neurosurgery and Psychiatry 2014; 85(10):e4.

https://doi.org/10.1136/jnnp-2014-

309236.98

8. Swaiman's Paediatric Neurology Principles and Practice. Fifth edition Page 887.

9. Camfield P, Andermann F. Successful treatment of two cases of alternating hemiplegia with acetazolamide. Neuropediatrics 2006; 37 (Congress Abstract) https://doi.org/10.1055/s-2006-945585 